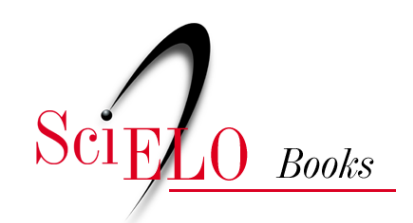

\title{
Capítulo tercero \\ Licitud de las injerencias en las comunicaciones a la luz del derecho internacional penal
}

\author{
Joel M. F. Ramírez-Mendoza
}

\section{SciELO Books / SciELO Livros / SciELO Libros}

RAMÍREZ MENDONZA, J.M.F. Licitud de las injerencias en las comunicaciones a la luz del derecho internacional penal. In: Diferencias entre las reglas de exclusión probatoria colombiana e internacional penal. Análisis en tres casos de injerencias en comunicaciones privadas [online]. Bogotá: Editorial Universidad del Rosario, 2015, pp. 139-180. Opera prima collection. ISBN: 978-958738-658-5. https://doi.org/10.7476/9789587386585.0004.

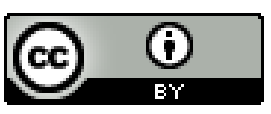

All the contents of this work, except where otherwise noted, is licensed under a Creative Commons Attribution 4.0 International license.

Todo o conteúdo deste trabalho, exceto quando houver ressalva, é publicado sob a licença Creative Commons Atribição 4.0.

Todo el contenido de esta obra, excepto donde se indique lo contrario, está bajo licencia de la licencia $\underline{\text { Creative }}$ Commons Reconocimento 4.0 . 


\section{Capítulo tercero Licitud de las injerencias en las comunicaciones a la luz del derecho internacional penal}

\section{Introducción}

En este capítulo entramos a estudiar cómo se ha venido desarrollando la regla de exclusión más reciente del derecho internacional penal (DIP). Sin embargo, puesto que esta no ha tenido la misma evolución que en los tribunales ad hoc, también la estudiaremos a partir del desarrollo del Tribunal Penal Internacional para la ex-Yugoslavia (TPIY) y los aportes del Tribunal Penal Internacional para Ruanda (TPIR), ya que son muy similares. Finalmente, se revisará cómo se aplicaría la regla extraída de los puntos comunes del derecho internacional penal a los tres casos expuestos en la introducción del presente trabajo.

\subsection{Las interceptaciones a la Luz del Estatuto de Roma y la Corte Penal Internacional}

Antes de adentrarnos en este punto, es importante hacer una breve introducción al procedimiento de la CPI y algunos comentarios sobre la regulación probatoria, así como hemos hecho un resumen del procedimiento interno colombiano, 
para tener una visión panorámica de la legalidad procesal aplicable.

Para que se active la competencia de la CPI se requiere que se cumplan los requisitos de competencia que establece el Estatuto, teniendo en cuenta la materia de los delitos, el lugar donde se cometieron, el momento de los hechos y la persona a quien se investigue. ${ }^{1}$ Dependiendo de esto, lo primero es analizar el contexto donde se produjeron los hechos, lo que la Corte llama "situación", o "abrir situación”. De esta manera, una de las situaciones que la Corte conoce son los conflictos armados, en cuanto que los crímenes de guerra hacen parte de su competencia gracias al art. 8. ${ }^{\circ}$. Después de un trabajo mancomunado entre la Sala de Cuestiones Preliminares y la Fiscalía, se abre una situación en concreto y se comienza a adelantar la investigación de casos propiamente dichos, los que deben tener una relación con la situación que se aprobó. ${ }^{2}$

El procedimiento ante la CPI principalmente se adelanta ante tres magistraturas. La primera de ellas es la Sala de Cuestiones Preliminares, la que aparte de revisar la apertu-

\footnotetext{
1 Revisar los arts. 5-17, 24-26, 53, 98, 124 del ER.

2 Cfr., Olásolo, Héctor. Corte Penal Internacional ¿Dónde investigar? Especial referencia a la Fiscalia en el proceso de activación. Edit. Tirant Lo Blanch, Cruz Roja Española. Valencia, 2002, p. 113; y Olásolo, Héctor. Admisibilidad de situaciones y casos objeto de procesos de justicia de transición ante la Corte Penal Internacional. En: Olásolo, Héctor. Ensayos de derecho penal y procesal internacional. Con inclusión de la lección inaugural de la Universidad de Utrecht (Holanda) dictada el 18 de octubre de 2010. Biblioteca Jurídica Diké, Instituto Iberoamericano de la Haya, Unión Europea, República de Colombia-Ministerio de Justicia y del Derecho. Bogotá, 2011, p. 124.
} 
ra de la situación, confirma los cargos que se le imputan al procesado. ${ }^{3}$ Posteriormente, ante la Sala de primera instancia se adelantará propiamente el juicio, donde se practicarán y debatirán las pruebas, se adelantarán los alegatos finales y se llegará a una sentencia en la que se fijará la absolución o condena y su pena. ${ }^{4}$ Contra esta sentencia caben los recursos de apelación y revisión ante la Sala de Apelaciones. ${ }^{5}$

Ahora, en materia probatoria, las tres salas tienen las mismas atribuciones, reguladas en el art. 69. ${ }^{6}$ Para que se practiquen las pruebas se deberá tener en cuenta la pertinencia, admisibilidad, su valor probatorio, y si puede ocasionar algún perjuicio al proceso; ${ }^{7}$ se respetarán los derechos de la defensa, los privilegios de confidencialidad, salvo aquellos que sean hechos notorios. ${ }^{8}$ En el caso de que afecte uno de estos puntos, se podrán excluir las pruebas que hayan sido obtenidas violando derechos humanos internacionalmente reconocidos, y que además, o viole la fiabilidad de la prueba, o viole el Estatuto o la integridad del juicio.?

3 Cfr., Arts. 56-61 del ER.

4 Cfr., Arts. 62-80 del ER.

5 Cfr., Arts. 81-85 del ER.

6 Si bien el Estatuto no lo dice expresamente, se entiende esto en cuanto que el art. 69 hace parte de la práctica de evidencia en la Sala de Juicio, y se extiende este a la Sala de Apelaciones en concordancia al art. 83.1. Por su parte, a la Sala de Cuestiones Preliminares el art. 56.2.f le permite "adoptar las medidas necesarias para reunir o preservar las pruebas".

7 Cfr., art. 69.3 del ER en concordancia con los arts. 64, 69.4 y 69.8 del mismo.

8 Cfr., arts. 67, 69.5 y 69.6 del ER.

9 Cfr., art. 69.7 del ER. 


\subsubsection{La relación del DIH y el DIDH con el Estatuto de Roma (ER)}

$\mathrm{Al}$ aproximarse a los Crímenes de Guerra, dentro del art. 8. ${ }^{\circ}$, num. 2 del ER., con respecto a los conflictos armados no internacionales, el lit. c. hace una remisión directa al art. 3 común a los Convenios de Ginebra, y el lit. e. hace remisión mucho más amplia al decir "dentro del marco establecido de derecho internacional"; de esta manera no solo cabe la remisión al DIH y al DIDH sino a cualquier instrumento que pueda tener alguna aplicabilidad para los crímenes enlistados en el citado lit. e. Es importante señalar que el desarrollo jurisprudencial de la CPI se ha dado en menor medida que en otros organismos internacionales como el TPIY o el Tribunal Penal Internacional para Ruanda (TPIR). Ante esto precisamente el art. 21 del Estatuto, admite otras fuentes para aplicar e interpretar el ER y las Reglas de Procedimiento y Prueba (RPP). ${ }^{10}$

10 Conferencia Diplomática de plenipotenciarios de las Naciones Unidas. Estatuto de la Corte Penal Internacional (ER). Adoptada en Roma el 17 de julio de 1998.

Artículo 21. Derecho aplicable.

1. La Corte aplicará:

a) En primer lugar, el presente Estatuto, los Elementos de los crímenes y sus Reglas de Procedimiento y Prueba;

b) En segundo lugar, cuando proceda, los tratados aplicables, los principios y normas del derecho internacional, incluidos los principios establecidos del derecho internacional de los conflictos armados;

$[\ldots]$

3. La aplicación e interpretación del derecho de conformidad con el presente artículo deberá ser compatible con los derechos humanos internacionalmente reconocidos, sin distinción alguna basada en motivos como el género, definido en el párrafo 3 del artículo 7, la edad, la raza, el color, el idioma, la religión o el credo, la opinión política o de otra índole, 
Así, para entender el ER primero se estudia aquello que se encuentre dentro de los Elementos de los Crímenes y de las RPP, seguidamente se estudia este cuerpo normativo en concordancia con los demás tratados aplicables, donde si bien nombra expresamente el DIH no excluye la aplicabilidad del DIDH ni la jurisprudencia de los diferentes tribunales internacionales como el TPIY o el TPIR, o las Cortes de Derechos Humanos. ${ }^{11}$ El num. 3 condiciona la aplicación y la interpretación del derecho a partir del artículo 21, debe ser compatible con el DIDH, y se prohíbe expresamente cualquier tratamiento discriminativo.

Por lo tanto, las garantías judiciales terminan siendo claves dentro del DIP, y dentro del contexto del conflicto armado no internacional: primero, porque el DIH establece en su art. 3 común la protección de las garantías judiciales; y segundo, por parte del DIDH, estas no podrán ser suspendidas en ningún momento.

el origen nacional, étnico o social, la posición económica, el nacimiento u otra condición.

11 Ante esto, el art. 38 del Estatuto de la Corte Internacional de Justicia dice:

1. La Corte, cuya función es decidir conforme al derecho internacional las controversias que le sean sometidas, deberá aplicar: a) las convenciones internacionales, sean generales o particulares, que establecen reglas expresamente reconocidas por los Estados litigantes; b) la costumbre internacional como prueba de una práctica generalmente aceptada como derecho; c) los principios generales de derecho reconocidos por las naciones civilizadas; d) las decisiones judiciales y las doctrinas de los publicistas de mayor competencia de las distintas naciones, como medio auxiliar para la determinación de las reglas de derecho, sin perjuicio de lo dispuesto en el artículo 59; 2. La presente disposición no restringe la facultad de la Corte para decidir un litigio ex aequo et bono, si las partes así lo convinieren. 


\subsubsection{La admisibilidad de la prueba producida por injerencias a la intimidad ante la Corte Penal Internacional}

El art. 69 del ER trata de la prueba en concreto. En lo que respecta a nuestro interés, nos vamos a enfocar en la admisibilidad y la regla de exclusión regulados en los nums. 4 y 7 de dicho artículo:

Artículo 69 Práctica de las pruebas.

[...]

4. La Corte podrá decidir sobre la relevancia o admisibilidad de cualquier prueba, teniendo en cuenta, entre otras cosas, su valor probatorio y cualquier perjuicio que pueda suponer para un juicio justo o para la justa evaluación del testimonio de un testigo, de conformidad con las Reglas de Procedimiento y Prueba.

$[\ldots]$

7. No serán admisibles las pruebas obtenidas como resultado de una violación del presente Estatuto o de las normas de derechos humanos internacionalmente reconocidas cuando:

a) Esa violación suscite serias dudas sobre la fiabilidad de las pruebas; o

b) Su admisión atente contra la integridad del juicio o redunde en grave desmedro de él. ${ }^{12}$

12 ER. Supra.n. 240. 
En las RPp de la CPI, su Regla 63.3 dice que "La Sala se pronunciará sobre las cuestiones de admisibilidad fundadas en las causales enunciadas en el párrafo 7 del artículo 69 que plantee una de las partes o ella misma de oficio de conformidad con el párrafo 9 a) del artículo $64 " .{ }^{13}$

Dicho reenvío faculta a la Sala de Primera Instancia, ya sea por petición de parte o de manera oficiosa, para decidir sobre la admisibilidad o pertinencia de las pruebas. Eso nos lleva a tratar la regla de exclusión de manera similar a la admisibilidad probatoria. Seguidamente, la Regla 64.1 dice:

Las cuestiones de pertinencia o admisibilidad deberán plantearse en el momento en que la prueba sea presentada ante una de las Salas. Excepcionalmente, podrán plantearse inmediatamente después de conocida la causal de falta de pertinencia o inadmisibilidad cuando no se haya conocido al momento en que la prueba haya sido presentada. La Sala podrá solicitar que la cuestión se plantee por escrito. La Corte transmitirá el escrito a todos los que participen en el proceso, a menos que decida otra cosa.

La regla 64.2 consiste en que "la sala expondrá las razones de los dictámenes que emitan sobre cuestiones de prueba” y dichas razones tendrán que constar en el expediente. La regla 64.3 trata de que las pruebas que se hayan declarado inadmisibles o impertinentes no serán valoradas. Si bien en

13 Corte Penal Internacional, Asamblea de los Estados Partes. Reglas de Procedimiento y Prueba. ICC-ASP/1/3 (Part. II-A) de 9 de septiembre de 2002. 
estas hay varios puntos de la admisibilidad que se estudian, la profesora Buisman los reduce a cuatro puntos: la relevancia, el valor probatorio, el perjuicio que pueda ocasionar en el proceso, y la fiabilidad. ${ }^{14}$ Sin embargo, nos vamos a concentrar en dos puntos comunes tanto en la admisibilidad como en la regla de exclusión: la fiabilidad de la prueba y el perjuicio de la prueba en el proceso. Si bien es cierto el art. 69.7 dice que para que se excluya una prueba se requiere que haya una violación del ER o de algún derecho internacionalmente reconocido, esto se tiene que analizar a la vista de estos dos puntos comunes. ${ }^{15}$ Sin embargo, es importante señalar que el enunciado general relaciona la violación con la normativa internacional, de tal manera que no toma la segunda parte de la postura de la doctrina Schenck, que corresponde en revisar el cumplimiento de las garantías judiciales a la luz del derecho interno.

Al tener en cuenta la regla 64, el momento procesal para estudiar la admisibilidad es cuando se presenta ante la Sala la

14 Buisman, Caroline. Evidence before International Criminal Courts and Tribunals. En Bantekas, Ilias International Criminal Law. 4. ${ }^{a}$ ed. Hart Publishing Ltd., Oxford, 2010, pp. 473-547; Cfr., Schabas, William A. The International Criminal Court: Comentary on the Rome Statute. Oxford University Press. Oxford, 2010, pp. 843-845. Hay que tener en cuenta que la CPI se enfoca en los tres primeros puntos y la fiabilidad se estudia desde la relevancia; Cfr., CPI, Situación de República Democrática del Congo. Sala de Primera Instancia I, Prosecutor v. Thomas Lubanga Dyilo. Corrigendum to Decision on the admissibility of four documents (ICC-01/04-01/06-1399-Corr) de 20 de enero de 2011, párrs. 26-32.

15 CPI, Situación de República Democrática del Congo. Sala de Cuestiones Preliminares I, Prosecutor v. Thomas Lubanga Dyilo. Decision on the confirmation of charges (ICC-01/04-01/06-803-tEN) de 29 de enero de 2007, párr. 84. 
prueba que se desea practicar. Sin embargo, también puede ser con posterioridad a que se presente la prueba dado que el art 64.9 amplía esta potestad a la Sala de Primera Instancia para estudiar la admisibilidad y relevancia sobre las pruebas; en concordancia con la regla 63.1, amplía todo el art. 64 del Estatuto a todas las Salas de la CPI. ${ }^{16}$ Hay que resaltar que este análisis no es solamente de la Sala de Primera Instancia, sino que también puede llegar a presentarse tanto en la Sala de Cuestiones Preliminares como en la Sala de Apelaciones. Esto sucede en función del art. 83.1 y 2 del ER y la regla 63.1 de las RPP, y por tanto se infiere que la regla de exclusión se puede dar en cualquier momento procesal. De esta manera, la regla de exclusión es uno de los mecanismos para remediar las infracciones a los derechos de las partes, principalmente los derechos del acusado. ${ }^{17}$

\subsubsection{La fiabilidad de la prueba}

Entre los diferentes medios probatorios - cada uno puede tener una reglamentación o exigencias propias - se destacan los siguientes: el testimonio, el reporte del investigador o

16 Cfr., CPI, Situación de la República Centroafricana. Sala de Apelaciones, Prosecutor v. Jean Pierre Bemba Gombo. Sentencia relativa a las apelaciones del Sr. Jean-Pierre Bemba Gombo y el fiscal contra la decisión de la Sala de Primera Instancia III titulada "Decisión relativa a la admisión como pruebas de los materiales contenidos en la lista de pruebas de la Fiscalía” (ICC-01/0501/08-1386-tSPA) de 3 de mayo de 2011, párr. 37.

17 Cfr., Cherif Bassiouni, Mahmoud. Issues Pertaining to the Evidentiary Part of International Criminal Law. En: Cherif Bassiouni, Mahmoud (Edit.) International Criminal Law. 3. a ed., Martinus Nijhoff Publishers, Leiden, 2008, pp. 597-598. 
forense, la prueba del perito o experto y la prueba documental. ${ }^{18}$ Por lo que entendemos, las interceptaciones de comunicaciones corresponderían más a una prueba documental, puesto que en esta cabrían las grabaciones por cualquier medio, como veremos más adelante.

Para que una prueba sea fiable se evalúa principalmente su procedencia, aunque no excluye otros elementos que las Salas pueden considerar relevantes, y por tanto se busca establecer su autenticidad a partir de saber quién es el autor del documento y su relación con el hecho o evento que se desea probar; por lo tanto, la cadena de custodia tiene un papel importante, que abarca desde el momento de creación el documento hasta cuando este se aporta a la Sala. Sin embargo, a pesar de que el documento pueda ser auténtico, no se puede inferir automáticamente su fiabilidad. ${ }^{19}$

Hay que tener en cuenta que la fiabilidad también hace parte del análisis sobre el valor probatorio de una prueba en concreto, enlazando así el art. 69.7 (a) con el art. 69.4 ER, puesto que la regla de exclusión consiste en estudiar si los medios técnicos o el método del cual se obtuvo la prueba y su preservación permite afirmar que esta es fiable, como es el

18 Cfr., Buisman, Caroline. Op. cit., pp. 487-521; Cfr., Cherif Bassiouni, Mahmoud Issues Pertaining to the Evidentiary Part of International Criminal Law... Op. cit., pp. 586-592.

19 Cfr., CPI, Situación de República Democrática del Congo. Sala de Primera Instancia II, Prosecutor v. Matbieu Ngudjolo. Judgment pursuant to article 74 of the Statute (ICC-01/04-02/12-3) de 18 de diciembre de 2012, párr. 57; Cfr., CPI, Situación de República Democrática del Congo. Sala de Primera Instancia I, Prosecutor v. Thomas Lubanga Dyilo. Judgment pursuant to article 74 of the Statute (ICC-01/04-01/06-2842) de 14 de marzo de 2012, párr. 109. 
caso de una ruptura de la cadena de custodia, donde no solo afecta la fiabilidad del art. 69.7 (a), sino que además afecta el valor probatorio del art. $69.4 .^{20}$ Con respecto al perjuicio al proceso, primero se hace un análisis de proporcionalidad entre el derecho reconocido internacionalmente con la fiabilidad de la prueba obtenida y, por tanto, la exclusión de la prueba se da cuando la vulneración de un derecho afecte esa fiabilidad. ${ }^{21}$ En el caso de que no prospere el análisis con el derecho internacional, la causal se adelantaría por el art. 69.7. (b).

Por otra parte, este procedimiento se rige por el principio de oralidad, teniendo en cuenta que se deben allegar al proceso las pruebas que busquen establecer la verdad de acuerdo con al art. 69.3 del Estatuto, y observando la protección de los derechos del acusado según el art. 64.2 del mismo. De esta manera, si bien es cierto que hay una referencia expresa a la oralidad por medio del art. 69.2, se puede utilizar cualquier medio de prueba que resulte necesario para probar un hecho; es decir, el ER acoge con amplitud el principio de libertad probatoria. ${ }^{22}$

20 Cfr., Schabas, William. The UN International Criminal Tribunals. The former Yugoslavia, Rwanda and Sierra Leona. Cambridge University Press, New York, 2006, pp. 456-457.

21 CPI, Situación de República Democrática del Congo. Sala de Cuestiones Preliminares I, Prosecutor v. Thomas Lubanga Dyilo. Decision on the confirmation of charges (ICC-01/04-01/06-803-tEN) de 29 de enero de 2007, párr. 85; TPIY, Sala de Primera Instancia, Prosecutor v. Karadžić, Radovan. Decision on the accused's motion to exclude Intercepted Conversations (IT-95-5/18-T) de 30 de septiembre de 2010, párr. 6.

22 Cfr., cPI, Situación de República Democrática del Congo. Sala de Cues- 


\subsubsection{El perjuicio al Estatuto o al juicio}

Con respecto al perjuicio al Estatuto, o del juicio mismo, se hace un análisis de proporcionalidad, pero en este caso es entre el deber de atacar la impunidad a partir de la responsabilidad del acusado ante las víctimas y la comunidad internacional, y la protección de un juicio justo y los demás derechos del acusado. ${ }^{23} \mathrm{~A}$ este respecto, corresponde estudiar en este punto cuándo se vulnera las RPP o directamente al Estatuto. ${ }^{24}$

En el caso Lubanga, donde se trata el derecho a la intimidad - dado que, tras un allanamiento, se incautan evidencias -, si bien este es violatorio del derecho interno (referente al Código de Procedimiento Congolés), el análisis se hace a la luz del ER, y por ello estas pruebas se admiten porque no se afecta la fiabilidad de las evidencias obtenidas argumentando desde los arts. 69.4 y 69.7..$^{25}$ Así, a pesar de que la prueba se obtuvo fuera de lo regulado por el derecho

tiones Preliminares I, Prosecutor v. Thomas Lubanga Dyilo. Corrigendum to Decision on the admissibility of four documents (ICC-01/04-01/06-1399-Corr) de 20 de enero de 2011, párrs. 19-25.

23 Cfr., cPI, Situación de República Democrática del Congo. Sala de Cuestiones Preliminares I, Prosecutor v. Thomas Lubanga Dyilo. Decision on the confirmation of charges (ICC-01/04-01/06-803-tEN) del 29 de enero de 2007, párr. 85; Cfr., TPIY, Sala de Primera Instancia. Prosecutor v. Karadžić, Radovan. Decision on the accused's motion to exclude Intercepted Conversations (IT-95-5/18-T) de 30 de septiembre de 2010, párr. 7.

24 Cfr., Buisman, Caroline. Op. cit., pp. 524-530.

25 Cfr., CPI, Situación de República Democrática del Congo. Sala de Cuestiones Preliminares I. Prosecutor v. Thomas Lubanga Dyilo. Decision on the confirmation of charges (ICC-01/04-01/06-803-tEN) de 29 de enero de 2007, párrs. 62, 90. 
doméstico, como es en este caso el de la República del Congo, no se afecta la decisión de admitir la prueba, a diferencia de como se trata en los sistemas de derechos humanos; por otra parte, en este allanamiento, si bien hubo una violación al derecho a la intimidad, parece no afectar ni el juicio ni el Estatuto de Roma.

La Sala de Cuestiones Preliminares II en el caso JeanPierre Bemba excluye la prueba referente a los comportamientos sexuales anteriores o posteriores de la víctima, cuando se trate de probar crímenes de violencia sexual según la regla $71 .{ }^{26}$ Schabas nos explica que en el common law el jurado puede ser injustamente influenciado por los comportamientos anteriores de la víctima y por tanto ello puede perjudicar el proceso. ${ }^{27}$ Sin embargo, la Sala de Primera Instancia declaró la admisibilidad de las pruebas a partir de un análisis en conjunto a partir de las listas de pruebas presentadas por las partes. ${ }^{28}$ Tal decisión fue apelada y la Sala de Apelaciones consideró que las pruebas se debían declarar inadmisibles, o en su defecto ser excluidos, según

26 Cfr., CPI, Situación de República Centroafricana, Sala de Cuestiones Preliminares II. Caso de Prosecutor v. Jean Pierre Bemba. Decision Pursuant to Article 61(7) (a) and (b) of the Rome Statute on the Charges of the Against Jean-Pierre Bemba Gombo (ICC-01/05-01/08) del 15 de junio de 2009, párrs. 46, 51.

27 Schabas, William A. The International Criminal Court... Op. cit., pp. 844,845 .

28 Cfr. CPI, Situación de República Centroafricana, Sala de Primera Instancia III, Caso de Prosecutorv. Jean Pierre Bemba, Decision on the admission into evidence of materials contained in the prosecution's list of evidence (ICC01/05-01/08-1022) de 19 de noviembre de 2010, párr. 35. 
la regla 71. El análisis debió hacerse evidencia por evidencia, y no a partir de una lista; por lo tanto, la Sala de Apelaciones revocó la decisión de primera instancia y confirmó lo planteado por la Sala de Cuestiones Preliminares. ${ }^{29}$ De esta manera, encontramos que el lit. b. del art. 69.7 del Estatuto se cumple cuando se vulneran derechos de las partes o lo reglado en la normatividad del ER o las RPP.

Vemos en el caso Callixte Mbarushimana que nuevamente se intenta excluir la interceptación de comunicaciones a partir de su falta de fiabilidad. Generalmente los medios probatorios producidos a partir de injerencias en las comunicaciones privadas, como es el caso de las interceptaciones, tiende a alegarse a partir de su falta de fiabilidad, mostrando que estas no son auténticas; esta es la principal vía para su exclusión, dado que el daño al derecho a la intimidad no alcanza el umbral necesario para la exclusión, como sí sucede con la tortura o tratamientos inhumanos. ${ }^{30}$ Esta postura es tomada del TPIY, como veremos seguidamente.

29 Cfr., CPI, Situación de República Centroafricana, Sala de Apelaciones, Caso de Prosecutor v. Jean-Pierre Bemba. "Sentencia relativa a las apelaciones del Sr. Jean-Pierre Bemba Gombo y el Fiscal contra la decisión de la Sala de Primera Instancia III, titulada 'Decisión relativa a la admisión como pruebas de los materiales contenidos en la lista de pruebas de la Fiscalía'" (ICC-01/0501/08-1386-tSPA) del 3 de mayo de 2011, párrs. 52, 53.

30 Cfr., CPI, Situación de República Democrática del Congo. Sala de Cuestiones Preliminares I, Prosecutor v. Callixte Mbarushimana. Decision on the confirmation of charges (ICC-01/04-01/10-465-Red) de 16 de diciembre de 2011, párrs. 71-74. 


\subsection{Las interceptaciones de comunicaciones a la luz del TPIY}

Vemos que la CPI no ha tenido el mismo desarrollo que ha tenido el TPIY. Por tal razón, gracias al art. 21, que trata el sistema de fuentes, nos permite remitirnos a este tribunal, sin dejar de lado las contribuciones del TPIR, al explicar de una mejor manera qué son las pruebas documentales y sus requisitos de fiabilidad.

\subsubsection{La admisibilidad de la prueba obtenida por injerencias a la intimidad ante el TPIY}

Resulta necesario revisar en conjunto los criterios de admisibilidad en el contexto del art. 89 de las RPP del TPIY:

Artículo 89.

Disposiciones generales (Aprobado el 11 de feb de 1994)

(a) La Sala deberá aplicar las reglas de la prueba establecidas en esta sección, y no estará obligado por las reglas nacionales de pruebas. (Modificado 13 dic de 2000).

(b) En los casos no previstos en la presente sección, la Sala deberá aplicar las reglas de evidencia que mejor favorezca a una determinación justa sobre el asunto y estar en consonancia con el espíritu del estatuto y los principios generales del derecho.

(c) La Sala podrá admitir la prueba relevante que considera tener valor probatorio.

(d) La Sala podrá excluir la prueba si su valor probatorio sea (sic) sustancialmente inferior a la necesidad de garantizar un juicio imparcial. 
(e) La Sala podrá solicitar la verificación de la autenticidad de la prueba obtenida fuera de los tribunales.

(f) La Sala podrá recibir el testimonio oralmente o, cuando los intereses de la justicia lo permita, en forma escrita (modificado 13 dic. de 2000). ${ }^{31}$

Este regla del TPIY es concordante con el art. 69.4 del $\mathrm{ER}$, puesto que tienen en común el valor probatorio y la relevancia de la prueba. La regla de exclusión de la TPIY la encontramos en la regla 95:

Regla 95.

Exclusión de ciertas pruebas. (Aprobado 1994 de feb. 11, modificada 30 ene. de 1995, modificada 12 nov. de 1997) Ninguna prueba debe ser admisible si se obtuvo por métodos que arrojen dudas sustanciales sobre su fiabilidad o si su admisión va en contra y podría dañar seriamente la integridad del juicio. ${ }^{32}$

Sobre este punto es interesante ver que el enunciado general que plantea el art. 69.7 del ER se encuentra en la regla 89 (A) del TPIY. La diferencia consiste en que mientras en el TPIY por lo que dice la regla, se revisará solamente la viola-

31 Naciones Unidas, International Tribunal for the Prosecution of Persons Responsible for Serious Violations of International Humanitarian Law Committed in the Territory of the former Yugoslavia since 1991 (Tribunal Penal Internacional para la ex-Yugoslavia). Rules of procedure and evidence (IT/32/ Rev. 49) de 22 de mayo de 2013, regla 89.

32 Ibíd., regla 95. 
ción de su estatuto, en el ER, adicionalmente a su normativa, también está vinculado a las normas de derechos humanos internacionalmente reconocidos. Pero en cualquier caso, para que la regla de exclusión prospere se deberá afectar la fiabilidad de la prueba o que le produzca un perjuicio al proceso.

Es importante hacer dos precisiones: primero, cuando se estudia la fiabilidad de la prueba, se está estudiando al mismo tiempo su valor probatorio y su relevancia, puesto que si se considera, por ejemplo, que se rompe la cadena de custodia, la prueba deja de ser fiable, pierde su capacidad probatoria y deja de ser relevante en el proceso; segundo, cuando el ER y las RPP del TPIY regulan que se revisará la normativa que rige estos foros internacionales, se deja de lado uno de los puntos que trata la doctrina Schenck, que es el reenvío a los sistemas judiciales domésticos.

\subsubsection{La fiabilidad de la prueba}

Ahora, por la naturaleza de la interceptación de comunicaciones, el medio probatorio para introducirlas al proceso sería la prueba documental, ${ }^{33}$ la cual el TPIY ha entendido de la siguiente forma:

La prueba documental se compone de documentos como prueba para su evaluación por el Tribunal. A los efectos

33 TPIY, Sala de Primera Instancia, Prosecutorv. Karadžić, Radovan. Decision on the prosecution's motion for judicial notice of intercepts related to the Sarajevo component and request for leave to add one document to the rule 65 ter exhibit list (IT-95-5/18-T) de 4 de febrero de 2011, párr. 17. 
de este caso, el término 'documento' se interpreta en términos generales, se entiende que supone cualquier cosa en donde la información descrita es guardada. Esta interpretación es lo suficientemente amplia como para abarcar no sólo los documentos por escrito, sino también mapas, croquis, planos, calendarios, gráficos, dibujos, registros computarizados, registros mecánicos, registros electro-magnéticos, registros digitales, bases de datos, pistas de sonido, cintas de audio, cintas de video, fotografías, diapositivas y negativos. Muchos, aunque no todos, de estos tipos de documentos se produjeron en este caso por ambas partes en soporte de sus respectivos casos. ${ }^{34}$

Sin embargo, el TPIR ha aportado puntos importantes que se deben tener en cuenta para el análisis de este tipo de pruebas. Caroline Buisman, tomando como base el caso de Bogosora, ha señalado los siguientes puntos:

34 TPIR, Sala de Apelaciones, Prosecutor v. Musema (ICTR-96-13-A) de 27 de enero de 2000, párr. 53. (Traducción libre) Dice textualmente:

Documentary evidence consists of documents produced as evidence for evaluation by the Tribunal. For the purposes of this case, the term 'document' is interpreted broadly, being understood to mean anything in which information of any description is recorded. This interpretation is wide enough to cover not only documents in writing, but also maps, sketches, plans, calendars, graphs, drawings, computerized records, mechanical records, electro-magnetic records, digital records, databases, sound tracks, audio-tapes, video-tapes, photographs, slides and negatives. Many, though not all, of these types of documents were produced in this case by both parties in support of their respective cases.

Cfr., Cherif Bassiouni, Mahmoud. Introduction to International Criminal Law: Second Revised Edition. Editorial Martinus Nijhoff Publischers, Leiden, 2013, p. 863. 
1. El lugar donde el documento fue incautado

2. La cadena de custodia luego de la incautación del documento

3. Corroboración del contenido del documento con otras evidencias

4. La naturaleza del documento por sí mismo tal como la firma, sello, o la escritura a mano. ${ }^{35}$

Por otra parte, en el caso Musema se enumeran otros puntos adicionales que resultan relevantes para su análisis, como son:

1. Si el documento presentado a la Sala es un original o una copia. Los originales tendrán, por regla general, un valor probatorio mayor que las copias;

2. Si un documento es copia, es en modo alguno registrado o inscrito con cierta autoridad institucional;

3. Si se firma el documento, sellado, certificado, estampado o de cualquier otra manera oficialmente autorizado por una autoridad u organización;

4. Si el documento ha sido debidamente ejecutado. En términos generales, esto consiste en mostrar que fue escrito, producido o autorizado por la persona o parte quien pretende ser escrito, producido o autorizado. ${ }^{36}$

35 Buisman, Caroline. Op. cit., p. 505. Citando, entre otros, a: TPIR, Sala de Primera Instancia, Prosecutor v. Bogosora et al. Decision on admission of tab 19 of binder produced in connection with appearance of witness Maxwell Nkole (ICTR-98-41-T) de 13 de septiembre de 2004, párr. 8.

36 Cfr., TPIR, Sala de Primera Instancia, Caso Prosecutorv. Musema. Jud- 
De acuerdo con esto, podemos entender que no es una lista cerrada y por tanto se estudian diversos aspectos que traten la fiabilidad de la prueba según la lógica y la sana crítica, y por tal razón la cadena de custodia, el autor del documento y el procedimiento en que se produjo el documento terminan siendo de considerable importancia. Por ello, la parte que decida aportar una interceptación tiene que demostrar de manera específica y clara por qué la prueba es relevante y fiable, estudiando principalmente la autenticidad, y posteriormente la Sala revisa si la prueba perjudica al proceso o algún derecho del acusado. ${ }^{37}$

En el caso de interceptaciones, se estudia a los operadores o funcionarios que realizan la interceptación, y/o los participantes de la conversación. ${ }^{38}$ En algunos casos encontramos

gement (ICTR-96-13-A) del 27 de enero de 2000, párr. 67. (Traducción libre) Dice textualmente:

Whether the document provided to the Chamber is an original or a copy. Originals will, as a general rule, have a higher probative value than copies; whether, a document being a copy, is in any way registered or enrolled with some institutional authority; whether the document is signed, sealed, certified, stamped or in any other way officially authorized by some authority or organization; whether or not the document has been duly executed. In general terms this involves showing that it was written, produced or authorized by the person or party by whom it purports to be written, produced or authorized.

37 Cfr., TPIY, Sala de Primera Instancia, Prosecutor v. Mladic, Ratko. Decision on prosecution's bar table motion for the admission of intercepts: Srebrenica segment (IT-09-92-T) de 2 de mayo de 2013, párrs. 16, 17; y TPIY, Sala de Primera Instancia, Prosecutor v. Karadžić, Radovan. Decision on prosecution's third bar table motion for the admission of intercepts (Srebrenica) (IT-95-5/18T) de 24 de mayo de 2012, párr. 9.

38 Cfr., tpiY, Sala de Primera Instancia, Prosecutor v. Karadžić, Radovan. Decision on the prosecution's motion for judicial notice of intercepts related 
que el testigo por el cual se incorpora puede ser perito, o testigo experto, para garantizar que la conversación que se haya grabado pueda ser reconocida; para ello se pueden utilizar investigadores directamente de la oficina de la Fiscalía, o expertos en radio comunicaciones, donde no solamente se debate sobre la autenticidad de las grabaciones, dado que en algunos casos se ha discutido la fabricación de conversaciones, y además se pueda garantizar el cumplimiento de la cadena de custodia para que estas no sufran modificaciones o manipulaciones. ${ }^{39}$ De esta manera, podemos afirmar que cuando en apreciación de la prueba se estudia la fiabilidad, también se revisa su autenticidad, cumpliendo así el requerimiento establecido por el CEDH en el caso Schenck.

Sin embargo, la mejor forma para aportar un documento al proceso es por medio de un testigo con la capacidad de responder las preguntas de las partes y, en especial, para que el acusado pueda contrainterrogar la prueba de cargo, garantizando el principio de contradicción. ${ }^{40}$

to the Sarajevo component and request for leave to add one document to the rule 65 ter exhibit list (IT-95-5/18-T) de 4 de febrero de 2011, párrs. 11-17, 27; y тPIY, Sala de Primera Instancia, Prosecutor v. Tolimir, Zdravko. Decision on prosecution's motion for admission of 28 intercepts from the bar table (IT05-88/2-T) de 20 de enero de 2012, párr. 14.

39 Cfr., TPIY, Sala de Primera Instancia, Prosecutor v. Popovic et al. Decision on Admisibility of intercepted communication (IT-05-88-T) de 7 de diciembre de 2007, párrs. 46, 54, 66-77; y TPIY, Sala de Primera instancia, Prosecutor v. Blagojevic and Jokic. Decision on the Admission into Evidence of Interceptrelated Materials (IT-02-60-T) de 18 de diciembre de 2003, párrs. 21-26.

40 Cfr., TPIY, Sala de Primera Instancia, Prosecutor v. Karadžić, Radovan. Decision on prosecution's first bar table motion for the admission of intercepts (IT-95-5/18-T), de 14 de mayo de 2012, párrs. 11; y TPIY, Sala de Primera 


\subsubsection{El perjuicio al Estatuto o al juicio}

A diferencia de lo que ha podido adelantar la CPI con respecto a este punto, es en el TPIY donde se ha trabajado más a fondo este tema. En este tribunal, en el caso Brdanin, se considera que aunque el derecho a la intimidad es un derecho internacionalmente reconocido, no es absoluto e incluso puede llegar a ser suspendido en estados de excepción, y las injerencias tienen que ser acordes a lo que regule la ley. ${ }^{41}$ Ahora, si bien es cierto una prueba que no se encuentra de acuerdo con lo regulado por la ley puede ser considerada ilícita, su admisión o su exclusión, según el caso, puede ser analizada bajo tres métodos:

1. En primer lugar, la propia ley establezca expresamente la exclusión automática de cualquier evidencia que haya sido ilegalmente o de otro modo obtenido indebidamente;

2. En segundo lugar, la cuestión de la exclusión o la admisión de dichas pruebas se puede dejar como un asunto a la discreción del juez que tiene el deber judicial para garantizar la imparcialidad hacia los acusados.

Instancia, Prosecutor v. Karadžić, Radovan. Decision on accused's motion for reconsideration of denial of defence intercepts (IT-95-5/18-T) de 22 de enero de 2013, párrs. 8, 9; y TPIY, Sala de Primera Instancia, Prosecutor v. Tolimir, Zdravko. Decision on prosecution's motion for admission of 28 intercepts from the bar table (IT-05-88/2-T) de 20 de enero de 2012, párr. 15.

41 Cfr., tPiy, Sala de Primera Instancia, Caso Prosecutor v. Brdanin, Radoslav. Decision on the defence objection to intercept evidence (IT -99-36-T) de 3 de octubre de 2003, párrs. 30, 31. 
3. En tercer lugar, los tribunales pueden ocuparse sólo con la calidad de las pruebas y no tener en cuenta su procedencia en absoluto; en otras palabras, los tribunales sólo tratarían de averiguar si la prueba es pertinente, confiable y si tiene valor probatorio, independientemente de las cuestiones de si la evidencia se obtuvo legal o ilegalmente. $^{42}$

El primer tipo de la regla de exclusión es el que principalmente se utiliza en los países de sistema continental, como es el caso colombiano, y las otras dos se usan principalmente en el common law. Ahora, el segundo tipo de exclusión es el sistema que principalmente utiliza el sistema norteamericano, mientras que el sistema inglés utiliza la tercera forma. ${ }^{43}$ En el ámbito internacional, el TPIY ha tenido en cuenta principalmente la postura de la $\mathrm{CEDH}$, la que toma los dos tipos de exclusión probatoria del sistema consuetudinario, adicionando que en el caso de que se cometa una violación a un derecho se debe tener un recurso efectivo para su protección; por tal razón, si bien se puede vulnerar el derecho a la intimidad, se revisa el derecho a un recurso efectivo y el debido proceso, tomando la postura del caso Schenck. ${ }^{44}$ Siendo así, como bien resalta el profesor Klamberg, las in-

42 Cfr., ibíd., párr. 33.

43 Cfr., ibíd., párrs. 35-40.

${ }_{44}$ Cfr., ibíd., párrs. 42-52. Citando a: CEDH, Caso Saunders v. Reino Unido, Caso Teixeira v. Portugal, Caso Schenk v. Suiza, Caso Khan v. Reino Unido, Caso P.G. and J.H. v. Reino Unido. Es importante resaltar que estudiar el debido proceso también incluye la regulación interna para que se puedan adelantar 
terceptaciones de comunicaciones no necesariamente afectan la integridad del proceso. ${ }^{45}$

Lo anterior se reafirma en la decisión oral en el caso Kordic, en el que se considera que el espionaje a partir de la interceptación de llamadas durante la guerra no afecta la integridad del proceso y por tal razón no se excluye. ${ }^{46}$ Las RPP del tribunal en esta materia no regulan la exclusión por la vulneración de un derecho concreto, como sucede en nuestro sistema doméstico, ${ }^{47}$ sino que se analiza a la luz de las garantías judiciales, como lo ha establecido la CEDH, situación que también sucede ante la CPI, solamente con respecto al análisis de la autenticidad de la prueba y haber otorgado la posibilidad de controvertirla, mas no se hace una remisión a los sistemas nacionales puesto que el procedimiento base es el del foro internacional, ya sea el del TPIY o el de la CPI. La exclusión de pruebas que son relevantes y tienen valor probatorio puede llegar a ser un obstáculo para la administración de justicia, y más aún cuando el ejercicio de esta contribuye a la restitución de la paz. ${ }^{48}$

las interceptaciones de comunicaciones; y СEDH, Caso Malone v. Reino Unido. Sentencia de 2 de agosto 1984.

45 Cfr., Klamberg, Mark. Evidence in international criminal Trials. Confronting legal Gaps and the Reconstruction of Disputed Events. Editorial Martinus Nijhoff Publishers, Leiden, 2013, p. 400.

46 Cfr., ibíd., párr. 53. Citando a: TPIY, Sala de Primera Instancia, Caso Prosecutor v Kordic and Cerkez (IT -99-36-T). Decisión oral del 2 de febrero de 2000. Transcripción 13694.

47 Cfr., ibíd., párr. 55.

48 Cfr., ibíd., párrs. 63, 67, citando a: TPIY, Sala de Primera Instancia, Pro- 
En el caso Celebici, se encuentra que hay una exclusión de la prueba en cuanto el procesado no contó con abogado durante el interrogatorio; y en el caso Martic se considera que la forma en que se consiguió el material probatorio no fue voluntario, sino que se obtuvo a partir de una conducta opresiva. ${ }^{49}$ En este caso encontramos, por una parte, que si una conducta se puede considerar como opresiva no es admisible bajo la regla 95 del TPIY, ${ }^{50}$ y también cuando una prueba puede vulnerar otro derecho, por fuera de una conducta opresiva, pareciera ser que se revisa bajo el estándar del caso Schenck en cuanto que se debe garantizar al procesado que pueda contradecir la prueba a partir de la autenticidad, relevancia y valor probatorio.

Por tal razón, en el caso Celebici no se admite la prueba por falta de representación de un abogado, y con ello no tendría cómo contradecir o alegar sobre el interrogatorio, pero en el caso de las interceptaciones no se afecta la integridad del proceso y no se logra desvirtuar la autenticidad de estas. Sin embargo, el caso Martic hace una exclusión debido a que la prueba se obtuvo con una conducta opresiva, lo cual per-

secutor v. Delalic et al. Decision On The Tendering Of Prosecution Exhibits 104-108 (IT-96-21-T) de 9 de febrero de 1998, párrs. 18-20.

49 Cfr., Klamberg, Marck. Op. cit., p. 401, citando a: TPIY, Sala de Primera Instancia, Prosecutor v. Delalic et al. Decision on Zdravko Mucic's motion for the exclusion of evidence (IT-96-21-T) de 2 de septiembre de 1997, párrs. 50-55; y tPIY, Sala de Primera Instancia, Prosecutor v. Martic, Milan. Decision adopting guidelines on the standards governing the admission of evidence (IT95-11-T) de 19 de enero de 2006, párr. 9.

50 Cfr., Klamberg, Marck. Op. cit., p. 402. 
judica al proceso, es decir que no necesariamente tiene que catalogarse como tortura para que proceda una exclusión.

En este orden de ideas, habría que revisar cuáles son los umbrales que afectan la regla 95 del TPIY. En el caso del ER, hay que estudiarlo como un todo para poder entender sus principios y valores que se encuentran reconocidos en el proceso establecido, principalmente los derechos de la defensa, y podrá ser interpretado según el DIH y el DIDH. ${ }^{51}$ Si bien se pueden encontrar diferentes principios, muchos de ellos se hallan regulados por los diferentes instrumentos internacionales relacionados con las garantías judiciales, y la dogmática ya ha podido reconocer algunos, como es el caso de la asesoría de un abogado o el descubrimiento probatorio, teniendo como remedio ante estas vulneraciones la exclusión de la prueba. ${ }^{52}$

\subsection{Casos de interceptaciones de comunicaciones en el desplazamiento forzado de Srebrenica}

Dado que la CPI no ha desarrollado suficientemente este tema, nos enfocamos en el TPIY para explicar de manera general el desplazamiento forzado de Srebrenica a partir de tres casos: Radislav Krstic, Zdravko Tolimir, Popovic et al. En estos, a diferencia de lo que sucede en los sistemas

51 Cfr., Klamberg, Marck. Op. cit., p. 405. Sin embargo, aquí se abre la pregunta, como en el caso Martic, si correspondería más a una regla de exclusión del sistema continental.

52 Cfr., Cherif Bassiouni, Mahmoud. Introduction to International Criminal Law... Op. cit., pp. 838-861. 
de derechos humanos, se estudiaron las interceptaciones de comunicaciones dentro del contexto de conflicto armado, siendo útiles para demostrar la planeación y la ejecución del desplazamiento forzado. Para ello, primero se explicará de manera general la desintegración de la ex-Yugoslavia y la formación de Bosnia y Herzegovina, luego expondremos los hechos ocurridos entre el 28 de junio y 12 de julio de 1995, cuando sucedió el desplazamiento forzado, y terminamos con las apreciaciones del Tribunal sobre las interceptaciones que allí sucedieron.

\subsubsection{Contexto grosso modo de Yugoslavia}

La región de Yugoslavia (tierra de los eslavos del sur) está comprendida entre el sur de Austria y el norte de Grecia, sobre los montes Balcanes, frente a Italia y separada de ella por el mar Adriático; es de textura muy accidentada, lo cual influye en que los poblados tiendan a ser estables y aislados. Esa situación geográfica permite explicar que a lo largo de la historia el norte (Eslovenia y Croacia) haya tenido especial influencia de Europa occidental, con sus resultados culturales como idioma y religión romana, mientras el centro y sur (Serbia, Bosnia-Herzegovina, Montenegro, Macedonia) tuvieron especial influencia griega y por lo tanto el alfabeto cirílico y la religión ortodoxa (cristiana del Imperio bizantino). La cultura musulmana del Imperio otomano buscó por muchos años derribar el Imperio romano de oriente y finalmente lo logró en 1453, y en su expansión estableció 
amplias comunidades en los Balcanes, incluso mayoritarias en muchas provincias. ${ }^{53}$

Al terminar la Segunda Guerra Mundial las seis repúblicas (Eslovenia, Croacia, Serbia, Bosnia-Herzegovina, Montenegro y Macedonia) conformaron la República Socialista Federal de Yugoslavia y lograron una destacada estabilidad y progreso, aunque siempre existieron tensiones por los diferentes factores que conforman las nacionalidades. Con la muerte del mariscal Joseph Broz Tito y la decadencia del socialismo europeo al finalizar la Guerra Fría, esas tensiones se exacerbaron. Croacia y Eslovenia declararon su independencia y la consolidaron tras una corta guerra. Después lo hizo Serbia, más tarde Macedonia, y finalmente Bosnia-Herzegovina y Montenegro. ${ }^{54}$

En Bosnia-Herzegovina se hizo especialmente difícil la definición de nacionalidades como Estados, pues la población estaba más mezclada, aunque no integrada. La presencia de bosnio-musulmanes (44\%), bosnio-serbios (31\%), y bosnio-croatas (17\%), donde muy pocas personas se declaraban simplemente bosnios o yugoslavos, y las pretensiones de pureza étnica, posiblemente recogiendo unidad idiomática, religiosa, o cultural, más la intervención de fuerzas extranjeras paramilitares comprometidas con cada una de las etnias o culturas involucradas, es la base so-

53 Asimov, Issac. Cronología del mundo. La historia del mundo desde el Big Bang a los tiempos modernos. Arial Ciencia. Barcelona, 1992, pp. 148, 149, 264, 265, 280, 281, 690-692.

54 Cfr., tpiY, Sala de Primera Instancia, Prosecutor v. Krstic, Radislav. Judgement (IT-98-33-T) de 2 de agosto de 2001, párrs. 7, 8, 9. 
bre la cual se desarrollan los actos de guerra en la que cada una buscaba un control territorial, y tienen lugar crímenes internacionales que obligan a la Naciones Unidas a crear el TPIY. Al este de Bosnia-Herzegovina, limitando con Serbia, cuya frontera es el río Drina, la principal tensión se daba entre los bosnios-serbios y los bosnios-musulmanes.

\section{Gráfico 1. Mapa de Bosnia y Herzegovina}

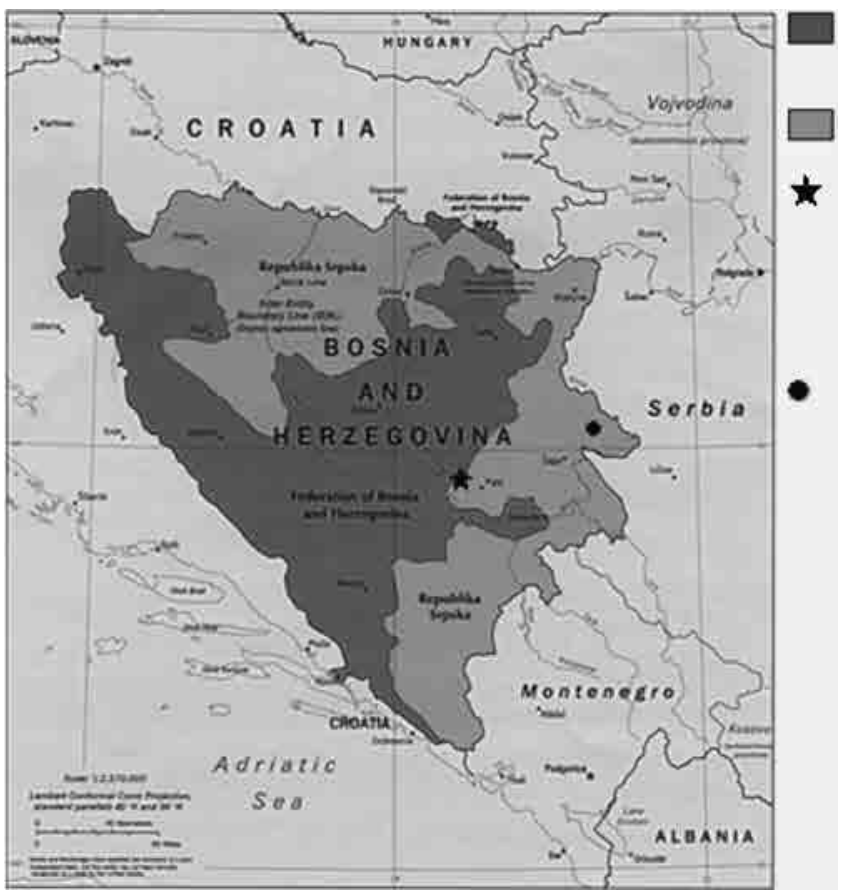

Federación de BosniaHerzegovina República de Sprska Sarajevo, Federación de BosniaHerzegovina, BosniaHerzegovina Srebrenica, República de Sprska, Bosnia Herzegovina

*Modificado sobre el mapa de Bosnia Herzegovina de la Universidad de Texas.

Fuente: http://www.lib.utexas.edu/maps/europe/bosnia_herzegovina/_pol97.jpg

Para 1991, Srebrenica era una ciudad con una población de un $73 \%$ bosnio-musulmán y un $25 \%$ bosnio-serbia, a 15 
kilómetros de la República de Serbia. Pese al porcentaje de los bosnios-musulmanes en Srebrenica, los bosnios-serbios querían tomar control de esta región para tener a los "Estados serbios" juntos. ${ }^{55}$ El 12 de mayo de 1992 la asamblea compuesta por los representantes de los bosnios serbios establece como objetivo constituir un corredor en el valle del río Drina, de tal manera que se separarían las dos etnias; en dicho territorio solo habría bosnios-serbios y constituirían la República de Srpska (Rs), ${ }^{56}$ como un Estado federado de Bosnia-Herzegovina.

El 16 de abril de 1993 el Consejo de Seguridad de las Naciones Unidas, con la Resolución 819, declara “área segura” a Srebrenica y sus alrededores (constituyendo el enclave de Srebrenica), que implicaba su desmilitarización. Por tal resolución, intervienen las Fuerzas de Protección de las Naciones Unidas (UNPROFOR) y hace presencia el Alto Comisionado de las Naciones Unidas para los Refugiados (UNHCR); se intenta evacuar a los bosnios musulmanes de esa región, pero el gobierno de estos se opone. ${ }^{57}$

\subsubsection{Desplazamiento forzado de la ciudad de Srebrenica}

El 28 de junio de 1995, el presidente de la Rs, Radovan Karadzic, y por tanto supremo comandante del Ejército de la RS (VRS) se comunicó con el mayor general Radislav Krstic,

55 Cfr., ibíd., párrs. 12, 13.

56 Cfr., TPIY, Sala de Primera Instancia, Caso Prosecutorv. Tolimir, Zdravko. Judgement (IT-05-88/2-T) del 12 de diciembre de 2012, párr. 162.

57 Cfr., ibíd., párr. 176. 
jefe de personal del Cuerpo Drina, ${ }^{58}$ siendo este parte del VRS, para preguntarle cuánto tiempo se necesita para tomar Srebrenica; este le respondió que aproximadamente cinco días, y así se comenzó a montar el plan de combate, cuyo nombre es "Krivaja 95" ${ }^{59} \mathrm{El} 2$ de julio se movilizaron ocho brigadas del Cuerpo Drina para preparar el ataque, y para ello tenían como objetivo separar los enclaves de Srebrenica y Zepa, ${ }^{60}$ reducir las áreas urbanas, posteriormente mejorar sus posiciones tácticas y eliminar los enclaves. ${ }^{61}$ En el enclave de Srebrenica el vrs estimaba la presencia de diez mil hombres de la $28^{\text {th }}$ División del Ejército de Bosnia-Herzegovina (A.BiH), pero el Batallón Holandés (DutchBat), que era parte de la UNPROFOR, calculaba la presencia entre tres mil y cuatro mil hombres. ${ }^{62}$

El 5 de julio se divide Krivaja 95 en dos grupos tácticos, se posicionan, y el combate empieza el 6 de julio a las tres de la mañana. El 7 de julio sigue el combate pero se comienza a bombardear el enclave de Srebrenica, y de igual forma se ataca el complejo del DutchBat en Potocari, un pueblo al

58 No sobra explicar que el Cuerpo Drina hace parte del vRs, y este a su vez se divide en Brigadas.

59 Cfr., Tpiy, Sala de Primera Instancia, Caso Prosecutor v. Popovic et al. Judgment (IT-05-88-T) del 10 junio de 2010, párrs. 242, 243.

60 El enclave de Zepa es colindante al sur occidente del enclave de Srebrenica.

61 Cfr., TPIy, Sala de Primera Instancia, Caso Prosecutor v. Tolimir, Zdravko. Judgment (IT-05-88/2-T) del 12 de diciembre de 2012, párr. 817; y TPIY, Sala de Primera Instancia, Prosecutor v. Krstic, Radislav. Judgment (IT-98-33-T) del 2 de agosto de 2001, párr. 120.

62 Cfr., TPIY, Sala de Primera Instancia, Prosecutor v. Popovic et al. Judgement (IT-05-88-T) del 10 junio de 2010, párr. 246. 
norte de la ciudad de Srebrenica. ${ }^{63}$ El 9 de julio se cambia el objetivo de reducir el área urbana del enclave, por el de tomar la ciudad. ${ }^{64} \mathrm{El} 10$ de julio distintos pueblos del enclave estaban siendo atacados, y eso lleva a que la mayoría de los bosnios-musulmanes se concentren en la ciudad de Srebrenica; esa misma noche el A.BiH. decide dejarla, tomando control el vrs de la ciudad el 11 de julio. Ese día se declara como municipio Serbio de Srebrenica. ${ }^{65}$

El 10 de julio, el vRs comenzó a movilizar varios miles de bosnios-musulmanes a Potocari, siendo recibidos por el DutchBat. ${ }^{66}$ Sin embargo, este batallón solo tuvo la capacidad de albergar entre 4.000 y 5.000 personas, y por tanto no pudieron seguir entrando al complejo del Batallón y ello lleva a que aproximadamente unos 20.000 bosnio-musulmanes quedaron esparcidos alrededor del complejo. ${ }^{67}$

63 Ibíd., párr. 249; Cfr., TPIY, Prosecutor v. Tolimir, Zdravko. Judgment (IT-05-88/2-T) del 12 de diciembre de 2012, párrs. 219, 220.

64 Cfr., TPIy, Sala de Primera Instancia, Prosecutor v. Popovic et al. Judgement (IT-05-88-T) del 10 junio de 2010, párr. 252; Cfr., TPIY, Caso Prosecutor v. Tolimir, Zdravko. Judgment (IT-05-88/2-T) del 12 de diciembre de 2012, párrs 226.

65 Cfr., TPIY, Sala de Primera Instancia, Prosecutor v. Popovic et al. Judgement (IT-05-88-T) del 10 junio de 2010, párrs. 255, 260, 262.

66 Cfr., TPIY, Sala de Primera Instancia, Prosecutor v. Popovic et al. Judgement (IT-05-88-T) del 10 junio de 2010, párrs. 257, 264, 266; y TPIY, Caso Prosecutorv. Tolimir, Zdravko. Judgement (IT-05-88/2-T) del 12 de diciembre de 2012, párrs. 233, 238, 241.

67 Cfr., TPIY, Sala de Primera Instancia, Prosecutor v. Popovic et al. Judgement (IT-05-88-T) del 10 junio de 2010, párr. 266; TPIY, Caso Prosecutor v. Tolimir, Zdravko. Judgement (IT-05-88/2-T) del 12 de diciembre de 2012, párr. 241; y TPIY, Caso Prosecutor v. Krstic, Radislav. Judgement (IT-98-33-T) del 2 de agosto de 2001, párr. 129. 


\section{Gráfico 2. Mapa de la región}

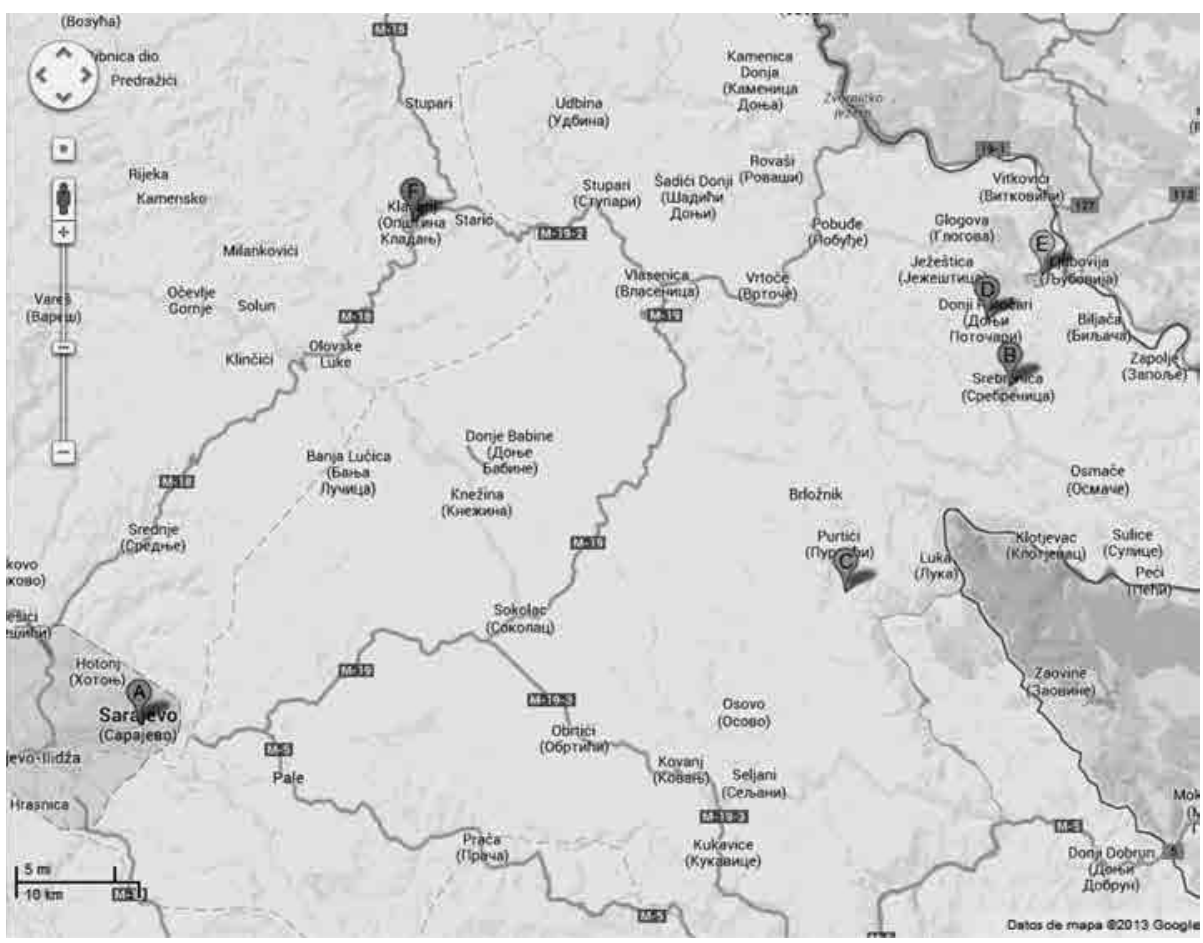

A: Sarajevo, Federación de Bosnia-Herzegovina, Bosnia-Herzegovina. B: Srebrenica, República de Sprska, Bosnia-Herzegovina. C: Zepa, República de Sprska, Bosnia-Herzegovina. D: Potocari, República de Sprska, Bosnia-Herzegovina. E: Bratunac, República de Sprska, Bosnia-Herzegovina. F: Kladanj, Federación de Bosnia-Herzegovina, Bosnia-Herzegovina.

*Modificaciones sobre el mapa de Google Maps.

Nota: La línea punteada marca el límite de lo que después sería a la fecha de estos hechos la Federación Bosnio-Herzegovino y la República de Sprska.

Entre 11 y el 12 de julio en la ciudad de Bratunac, en el Hotel Fontana se desarrolla una reunión entre el vRs, encabezado por Ratko Mladic, y el DutchBat, representado por el coronel Karremans, y representantes de los bosnio 
musulmanes. ${ }^{68}$ Karremans le informa a Mladic la situación humanitaria en que se encuentra Potocari ${ }^{69}$ y Mladic le responde que el objetivo de la operación era precisamente la evacuación de los bosnios musulmanes. ${ }^{70} \mathrm{La}$ situación del DutchBat era precaria con 20.000 refugiados alrededor de su complejo en graves condiciones humanitarias, ${ }^{71}$ por tanto, el 12 de julio a las 10 a.m. Mladic ofrece transportarlos, condicionando al DutchBat su colaboración con el combustible para los buses y la entrega de armamento de los bosnios-musulmanes, y estos aceptan, sin tener claridad completa de lo acordado. ${ }^{72} \mathrm{El} 17$ de julio, posteriormente a los hechos, llega el acuerdo por escrito donde señala que:

(1) que la población civil Bosnio Musulmana podría estar en el enclave o desalojarse, dependiendo de la voluntad de cada persona, (2) que la población civil Bosnio Musulmana puede ir a donde quiera si elige dejar el enclave, y que éstos habían elegido ser evacuados a Kladanj, y (3) que la evacuación estaría a cargo del vrs y de la po-

68 Cfr., TPIY, Sala de Primera Instancia, Prosecutor v. Popovic et al. Judgement (IT-05-88-T) del 10 junio de 2010, párr. 274; TPIY, Caso Prosecutor v. Tolimir, Zdravko. Judgement (IT-05-88/2-T) del 12 de diciembre de 2012, párr. 246; у тріу, Caso Prosecutor v. Krstic, Radislav. Judgement (IT-98-33-T) del 2 de agosto de 2001, párr. 126.

69 Cfr., TPIY, Sala de Primera Instancia, Prosecutor v. Popovic et al. Judgement (IT-05-88-T) del 10 junio de 2010, párrs. 275, 277.

70 Cfr., ibíd., párr. 275.

71 Cfr., ibíd., párrs. 309-315.

72 Cfr., ibíd., párrs. 279, 291. 
licía de la Rs, con supervisión y acompañamiento de la UNPROFOR durante la evacuación. ${ }^{73}$

Sin embargo, con anterioridad al acuerdo del 12 de julio a las 10 a.m., desde el 11 de julio por la noche Mladic se comunica con el Ministerio de Defensa del Rs solicitando buses que serían utilizados para el transporte de los bosnios musulmanes, y el 12 de julio a las 7:35 a.m. Krstic solicita al teniente coronel Krsmanovic, jefe de transporte del Cuerpo Drina, 50 buses desde diferentes municipios. Tienen como punto de encuentro el estadio de los deportes en la ciudad de Bratunac, y de allí serán llevados a Potocari para la "evacuación". ${ }^{74}$ Después Krstic se comunica con la Brigada Vlasenica, parte del Cuerpo Drina, para que estos se contacten con la policía de la Rs (MUP) para asegurar las rutas, por ejemplo removiendo minas y quitando barreras, para la evacuación hacia Kladanj, ciudad cercana al territorio del A.BiH. ${ }^{75}$ A pesar de que había acordado que el DutchBat daría el combustible, el vrs consiguió el combustible necesario para los buses y posteriormente se repone por parte

73 Ibíd., párr. 292.

74 Cfr., ibíd., párrs. 293, 294; TPIY, Caso Prosecutor v. Tolimir, Zdravko. Judgement (IT-05-88/2-T) del 12 de diciembre de 2012, párr. 270; y TPIY, Caso Prosecutorv. Krstic, Radislav. Judgement (IT-98-33-T) del 2 de agosto de 2001, párr. 138.

75 Cfr., TPIY, Sala de Primera Instancia, Prosecutor v. Popovic et al. Judgement (IT-05-88-T) del 10 junio de 2010, párr. 296; y TPIY, Caso Prosecutor v. Tolimir, Zdravko. Judgement (IT-05-88/2-T) del 12 de diciembre de 2012, párr. 274. 
del Batallón. ${ }^{76}$ Este mismo día por la mañana las unidades especiales del mup y la Brigada Bratunac (también del Cuerpo Drina), obtienen el control de Potocari. Después hacen una búsqueda exhaustiva de los refugiados alrededor del complejo del DutchBat con perros e incendiando casas. ${ }^{77}$

Finalmente, en lo que nos concierne, en la tarde del 12 de julio empiezan a llegar los buses al complejo del DutchBat ${ }^{78}$. Mladic da la orden de evacuar a todos los bosnios musulmanes, a pesar de lo que se había acordado. ${ }^{79}$ Antes de movilizarlos, la Policía Militar de la Brigada Bratunac separa los hombres, entre las edades de 15 a 65 años, de sus familias. ${ }^{80}$ Las mujeres, niños y ancianos son llevados Klandaj, mientras que los hombres fueron llevados a la ciudad de Bratunac. ${ }^{81}$ El transporte y la separación de los bosnio musulmanes continuó hasta el día siguiente, principalmente para los que estaban heridos. ${ }^{82}$ Estos hechos constituyen un desplazamiento forzado de la población bosnio-musulmana.

76 Cfr., TPiY, Sala de Primera Instancia, Prosecutor v. Popovic et al. Judgement (IT-05-88-T) del 10 junio de 2010, párrs. 297, 301; y TPIY, Caso Prosecutor v. Tolimir, Zdravko. Judgement (IT-05-88/2-T) del 12 de diciembre de 2012, párr. 271.

77 Cfr., TPIy, Sala de Primera Instancia, Prosecutor v. Popovic et al. Judgement (IT-05-88-T) del 10 junio de 2010, párrs. 302, 303, 305.

78 Ibíd., párr. 316.

79 Ibíd., párr. 318; Cfr., TPIY, Caso Prosecutor v. Tolimir, Zdravko. Judgement (IT-05-88/2-T) del 12 de diciembre de 2012, párr. 276; y TPIY, Caso Prosecutorv. Krstic, Radislav. Judgement (IT-98-33-T) del 2 de agosto de 2001, párr. 147.

80 Cfr., tPiy, Sala de Primera Instancia, Prosecutor v. Popovic et al. Judgement (IT-05-88-T) del 10 junio de 2010, párr. 319.

81 Ibíd., párrs. 332, 338.

82 Ibíd., Párrs. 323, 341. 


\subsubsection{Apreciaciones del Tribunal}

\section{sobre las interceptaciones de comunicaciones}

Esta reconstrucción del desplazamiento forzado de Srebrenica, si bien pareciera ser un caso con mayor detalle que con respecto a los tres casos nacionales anteriormente expuestos, son en realidad tres casos de TPIY sobre los mismos hechos, pero las personas a las que se acusa son diferentes; estos casos son Popovic et al, Tolimir y Krstic. Aquí vale la pena señalar que no se puede entender el alcance de una prueba sin comprender su contexto.

Las interceptaciones que hizo el A.BiH. al vRs fueron aportadas a la Fiscalía ante el TPIY por el gobierno bosnio. Ante esto la Fiscalía constituyó un grupo llamado "proyecto interceptación" (Intercept Project), que tiene por fin analizar, investigar y traducir las interceptaciones que se hayan obtenido por los diferentes sujetos del conflicto. Ahora, en el caso de las interceptaciones que hicieron los bosnios musulmanes, si bien no tenían el mejor nivel para ello, al cruzar la información con las pruebas obtenidas se encuentran coincidencias. ${ }^{83}$ Este procedimiento, para el Tribunal, le da suficiente fiabilidad al material probatorio, teniendo en cuenta no solo la forma en que se obtuvo la información, sino además el cuidado contra la ruptura de la cadena de custodia. ${ }^{84}$

83 Cfr., ibíd., párrs. 105, 107, 114; y TPIY, Caso Prosecutor v. Krstic, Radislav. Judgement (IT-98-33-T) del 2 de agosto de 2001, párrs. 105, 106.

84 Cfr., TPIy, Sala de Primera Instancia, Prosecutorv. Popovic et al. Judgement (IT-05-88-T) del 10 junio de 2010, párrs. 64, 116; TPIY, Caso Prosecutor v. Tolimir, Zdravko. Judgement (IT-05-88/2-T) del 12 de diciembre de 2012, párrs. 
De este resumido relato encontramos que las interceptaciones de comunicaciones sirvieron para probar cómo se movilizaron y se obtuvieron los buses, la seguridad de las rutas durante la evacuación por parte de la policía, la obtención del combustible y la orden de desplazar a todos los bosnios musulmanes a pesar del acuerdo. ${ }^{85}$ Acorde con ello, en los tres casos expuestos fueron condenados por el crimen de desplazamiento forzado y por otras conductas relacionadas con este, y también por el crimen de genocidio, entre otros. ${ }^{86}$ En los casos Popovic et al. y Tolimir, se intentó excluir las interceptaciones: en el primer caso porque no resultaban fiables; $y$ en el segundo, por la forma como se introdujo al proceso. Sin embargo, en ninguno de estos prosperó la petición de la defensa y se admitieron las interceptaciones, puesto que las salas consideraron que en efecto sí eran fiables y la introducción de estas al proceso estaban en regla. ${ }^{87}$

65, 66; y TPIY, Caso Prosecutor v. Krstic, Radislav. Judgement (IT-98-33-T) del 2 de agosto de 2001, párrs. 105-117.

85 Cfr., TPIY, Sala de Primera Instancia, Prosecutor v. Popovic et al. Judgement (IT-05-88-T) del 10 junio de 2010, párrs. 294, 286, 297, 318; тPIY, Caso Prosecutor v. Tolimir, Zdravko. Judgement (IT-05-88/2-T) del 12 de diciembre de 2012, párrs. 270, 271, 274, 276; y TPIY, Caso Prosecutor v. Krstic, Radislav. Judgement (IT-98-33-T) del 2 de agosto de 2001, parrs. 138, 147.

86 Cfr., tpry, Sala de Primera Instancia, Prosecutor v. Popovic et al. Judgement (IT-05-88-T) del 10 junio de 2010, Apartado IX; TPIY, Caso Prosecutor v. Tolimir, Zdravko. Judgement (IT-05-88/2-T) del 12 de diciembre de 2012, párr. 1239; у тріY, Caso Prosecutor v. Krstic, Radislav. Judgement (IT-98-33-T) del 2 de agosto de 2001, párr. 727.

87 TPIY, Sala de Primera Instancia, Caso Prosecutor v. Popovic et al. "Decisión on Admisibility of intercepted communication" (IT-05-88-T) del 7 de 
Es imperativo resaltar que todas las interceptaciones aportadas fueron hechas a las comunicaciones de la misma parte del conflicto armado. Por otra parte, si bien los que interceptaron también son sujetos activos, el análisis está más enfocado a la fiabilidad de los documentos aportados a la Fiscalía. De esta manera vemos que, a pesar de que el Tribunal no lo dice expresamente, se cumple el principio de distinción que ordena el DIH, como también lo establecido en la doctrina Schenck por la CEDH con respecto a garantizar la autenticidad de la prueba y la garantía de poder contradecir la prueba, excluyendo la remisión a los sistemas judiciales domésticos.

\section{Conclusiones: aplicación a los tres casos}

El TPIY, cuya jurisprudencia nos ayuda a interpretar el ER, toma la postura del caso Schenck, partiendo de la base de que la interceptación por sí misma no perjudica el juicio; si bien a la luz de la Corte Europea puede llegar a vulnerar el derecho a la privacidad, no es suficiente para alegar su exclusión ante la TPIY y la CPI. Sin embargo, como se expuso en el caso Lubanga, encontramos que se excluye la remisión al derecho doméstico, puesto que el referente que se debe estudiar es si hace algún perjuicio al Estatuto o a alguna normatividad internacional. En estos casos, generalmente se busca la exclusión probatoria a partir de alegar su no

diciembre de 2007, párrs. 46, 54, 66-77; y Cfr., TPIY, Sala de Primera instancia, Caso Prosecutor v. Tolimir, Zdravko. "Decision on prosecution's motion for admission of 28 intercepts from the bar table" (IT-05-88/2-T) de 20 de enero de 2012, párr. 15. 
autenticidad, situación diferente a un estado de coacción, o cuando se vulnera el derecho a la defensa, en los que la regla de exclusión sí prospera porque tiene un relación directa con el derecho a la defensa, como sucede en el caso Celebici, y la prohibición de uso de la prueba producida por tortura o cualquier forma de coacción, como se presenta en el caso Martic.

Por lo anterior, encontramos que el estándar de prueba de la regla de exclusión en la CPI es diferente a la regla de exclusión en el derecho colombiano. En la CPI, en el estudio de la exclusión si bien se observa si hubo una violación de un derecho humano, se condiciona adicionalmente que la prueba sea fiable, o que haya un perjuicio al estatuto o al proceso judicial. Lo que desarrolló la CEDH se puede ver en dos puntos: primero, se deben garantizar la autenticidad y la contradicción de la prueba; segundo, que la revisión de cumplimiento de las garantías judiciales debe hacerse en conjunto con los procedimientos legales que establecen los sistemas nacionales, lo que obliga a que haya una remisión al derecho interno. En nuestro caso, la regla de exclusión, como nosotros la entendemos, hace parte de las garantías judiciales domésticas. Sin embargo, el TPIY, solamente tomó la posición de la CEDH de revisar la autenticidad de la prueba y garantizar el principio de contradicción, sin revisar el cumplimiento de las garantías judiciales domésticas. La CPI, de acuerdo con su sistema de fuentes previsto en el art. 21 del ER, tomó la posición del TPIY.

De igual forma, el método que usó la Fiscalía ante la TPIY para confirmar la fiabilidad de la prueba fue revisar 
cada prueba de manera individual, y además hacer el estudio en conjunto de todas las pruebas. De tal manera que este requisito se debe estudiar desde los dos puntos de vista, de manera individual, y de manera conjunta, lo que no es novedad para el derecho colombiano, en cumplimiento del principio de unidad de la prueba.

Es importante señalar que al estudiar el caso del desplazamiento forzado de Srebrenica encontramos el cumplimiento del principio de distinción del DIH, puesto que todos los miembros a quienes se les interceptaron comunicaciones eran miembros activos del conflicto, así como también lo eran aquellos que interceptaron.

Si aplicamos esta regla de exclusión a nuestros tres casos, encontramos que en el primero el resultado puede ser diferente, y en los otros dos, la argumentación de la no exclusión puede variar:

1. En el caso de Juan Carlos Castillo, vemos que la autenticidad de la prueba se satisface puesto que la interceptación se hizo por parte de miembros de la inteligencia del Ejército Nacional, y como se pudo contradecir en primera instancia, la prueba no sería excluida.

2. En el caso de la masacre de Macayepo, se confirma la posición de la Corte Suprema de Justicia, y se deja de lado el debate de si la actividad que tuvo la SIPOL puede tener uso judicial. Sin embargo, aquí termina siendo sumamente importante la forma en que se puede adelantar la contradicción de la prueba, puesto 
que si no se logra debatir los métodos de cómo se obtuvo la información, se restringe el principio de contradicción de la prueba. La regla que plantea la Corte Constitucional de que la prueba producida en función de una orden judicial previa no se cumpliría en este caso, por lo que bastaría con revisar la autenticidad y contradicción de la prueba.

3. En el caso de la toma al Palacio de Justicia, la investigación se debe enfocar en si la capacidad que tenían las personas particulares que no tenían una participación directa en el conflicto satisface los requerimientos técnicos para garantizar la fiabilidad de la prueba. Sin embargo, también se puede aducir su fiabilidad a partir del cruce de información entre las diferentes grabaciones; cuando estas son concordantes, se puede decir que fueron auténticas, y por tanto tienen valor probatorio, siendo relevantes para el proceso. En este caso, la contradicción en que entra el Tribunal Superior de Bogotá con la regla general que estableció la Corte Constitucional, con respecto a si hubo o no una violación al derecho a la intimidad, no es relevante para esta regla de exclusión puesto que se pudo contradecir la prueba durante el proceso judicial. 